\title{
A implantação da Usina Hidrelétrica de Itaipu Binacional (Brasil/Paraguai) e a disputa pela terra no Brasil na década de 1970: entre a história e a memória
}

\author{
Maria de Fátima Bento Ribeiro ${ }^{1}$
}

\section{Resumo}

A instalação da hidrelétrica de Itaipu, na fronteira do Brasil com Paraguai, transformou-se em um episódio importante na história contemporânea, pois foi um projeto considerado de maior impacto na história de transformação da natureza e da ecologia do planeta, visto que a usina representou um impacto ambiental e de prejuízos humanos. Neste texto, temos o objetivo de analizar o discurso presente na Obra Entre a Cruz e a Política querelata eventos durante operíodo de instalação da Itaipu, contextualizando toda uma época. Tal discurso refletea questão da luta pela terra, do fortalecimento da oposição e seu crescimento nas cidades do oeste paranaense, principalmente com a formação do MDB naquela região. De modo geral, são memórias do cotidiano que ganham vida no interior de um discurso narrativo, e este material se faz importante para que a memória, na perspectiva das lutas populares, não caia no esquecimento.

Palavras-chave: Terra, Migrações, Fronteira, Itaipu, Memória.

\begin{abstract}
The installation of the hydroelectric plant from Itaipu, on the border of Brazil with Paraguay, it turned into an important episode in contemporary history, because it was a project considered of greater impact in the history of transformation of the nature and the ecology of the planet, seeing that the hydroelectric plant represented an environmental impact and human damages. In this text, we have the objective of analyzing the discourse presents in the book called Between the Cross and the Politics that it reports events during the installation period of Itaipu, contextualizing a whole epoch. This discourse reflects the question of the struggle for land, of the strengthening of the opposition and its growth in the cities of western Paraná, especially with the formation of the MDB in this region. Generally, it is memories of daily that won life inside a narrative discourse, and this material becomes important in order that memory, in the perspective of popular struggles, does not fall into forgetfulness
\end{abstract}

Key words: Land, Migration, Border, Itaipu, Memory.

\footnotetext{
1 Professora Dra. Maria de Fátima Bento Ribeiro, vinculada ao curso de Bacharelado em Relações Internacionais, da Universidade Federal de Pelotas (UFPEL). E-mail: mfabento@hotmail.com.

Recebido em 02/03/2017. Aprovado para publicação em 15/03/2017.
} 


\section{Considerações iniciais}

década de 1970, do século passado, foi uma época de profundas transformações A na fronteira do Brasil com o Paraguai, com a implantação da Itaipu Binacional, projeto considerado de maior impacto na história de transformação da natureza e da ecologia do planeta. Foi o momento dos grandes deslocamentos de agricultores e de suas famílias devido à construção do lago de Itaipu, o que ocasionou amigração para o norte do Brasil, como consequência a formação de várias cidades, transformando o antigo Território de Guaporé no Estado de Rondônia, como também ocasionou a penetração brasileira no Paraguai provocando uma questão em torno da problemática de sua soberania. Neste cenário, a política externa brasileira será de debates constantes quer com Argentina ou com Paraguai, e foi nesse contexto que os jornais do Brasil e de outros países cobriram a luta dos trabalhadores rurais.

Neste texto escolhemos, para trabalhar, uma série de pronunciamentos realizados por Gernote Kirinus ${ }^{2}$, na década em questão. Os pronunciamentos foram reunidos em uma obra intitulada Entre a Cruz e a Política, publicada pela Editora Beija-Flor, de Curitiba/Paraná ${ }^{3}$. livro é dividido em três capítulos: na primeira parte, constam os pronunciamentos (são 12 no total); na segunda parte, A Realidade Agrícola do Paraná e Trabalhos da Comissão de Terras, Colonização e Imigração, estão os trabalhos em comissões;e na terceira, contém entrevistas publicadas na imprensa, relativas ao período de março a junho de 1979, trazendo seus pronunciamentos nos primeiros meses de mandato no final da década de 70, na Assembleia Legislativa do Estado do Paraná (PR).

\footnotetext{
${ }^{2}$ Gernote Gilberto Kirinus nasceu em 1948, no município gaúcho de Não-Me-Toque.

${ }^{3}$ Trabalho realizado com base na apresentação no II Ciclo de Estudos e Debates do Grupo de Pesquisa Cultura, Relações de Gênero e Memória. Mesa Redonda: Memória da Resistência à Ditadura Militar no Oeste/Sudoeste Paranaense, ocorrido no ano de 2004, na Universidade Estadual do Oeste do Paraná (UNIOESTE), campus Toledo/PR.
} 


\section{CADERNOS DOCIM}

ANO I

VOLUME I

№ 1

JANEIRO/JUNHO 2017

PELOTAS/RS

ISSN 2526-5318

Constitui, no seu conjunto, uma fonte documental parapossíveis pesquisas nas mais diferentes áreas do saber: literatura, história, sociologia, antropologia, geografia, economia etc. E mais, são registros da memória de um dos períodosmais complexos da história brasileira.Desta forma, podemos afirmar que "com essa dramática carga individual e coletiva, a memória é concebida como valor e poder ético e, além disso, como um meio indubitável para instrumentalizar uma política" (Sosnowski, 1994, p. 15).

Neste caminho, concordamos com White (1999) quando escreve que é possívelcontar um grande número de "estórias" diferentes sobre o único acontecimento, em suas palavras, "porum arranjo específico dos acontecimentos, e sem prejuízo do valor de verdade dos fatos, selecionados, uma dada sequência de eventos pode ser urdida de inúmeras formas diferentes" (p. 77). Assim, encontramos também todo o imaginário de uma época, memória coletiva de uma região do país. Nos pronunciamentos de Kirinus, emergem a luta de pequenos agricultores explorados e expulsos de suas terras pela modernidade ocorrida nos campos devidoà mecanização da agricultura, pela violência causada pelos jagunços ou pelas águas do lago (represa) de Itaipu.

Este material faz parte da história e da memória da região em um momento de grande transformação eimpacto, não apenas dos espaços físicos, das paisagens, mas também da vida de milhares de pessoas e podecontribuir para que experiências vividas no passado portanto, a memória deste evento-sejam "reatualizadas" no presente, quer seja por historiadores ou por outro pesquisador.

Segundo Samuel (1997),"a memória longe de ser meramente um receptáculo passivo, ela é uma força ativa, que molda, que é dinâmica: o que a memória planeja esquecer é tão importante quanto o que ela lembra" (44).Nesse sentido, amemória reatualiza os eventos do passado, pois eles estão entrelaçados com a experiência presente, de acordo com De Decca (1999), "apaziguar os eventos do passado, assim se constitui o trabalho da História, muito diferente da memória que os reatualiza, exigindo que eles entrem novamente, na experiência do vivido, se debatam e se confrontam com o nosso presente"(p. 115). 


\section{CADERNOS DOCIM}

É nesse caminho que gostaríamos de situar esse trabalho, o livro relata várias frentes de luta, ora contra o "autoritarismo" dos prefeitos, então, nomeados, ora contra a forma como eram, tratados os agricultores, posseiros, arrendatários expulsos de suas terras, pelos jagunços/ estado. Sabemos por meio de pesquisas desenvolvidas no mestrado e doutorado queos agricultores se organizaram para conseguiram reverterem o preço que seria pago pelas suas terras, revelando-os longe da passividade que permearam os estudos do homem rural e sim como sujeitos ativos, que lutam por seus direitos, talvez tenha sido um equívoco trocarem o tema de suas reivindicações que no início era "terra por terra", por "queremos um preço justo pela terra", no entanto, o movimento provocou uma mudança significativa ao mostrarem a importância da luta, da união,da organização coletiva é essa foi sua grande forçanos seus protestos contra os direitos que estavam sendo retirados, no final dos protestos conseguiram um "preço mais justo" pelas suas terras. Sua força talvez não tenha vindo da vitória do movimento em si, uma vez, que a questão da terra continua sendo uma luta histórica em nosso país, mas foram revolucionáriosao servirem de referência para formação de outros movimentos sociais.

\section{Cidade, política e memória}

As belezas naturais e as terras consideradas férteis - motivo que ocasionou amigração para o Oeste do Paraná durante a década de 50 - são os pontos fortes da região paranaense, que, desde então, revelou-se como polo agrícola. Na década de 70, havia nesta área um grandenúmero de pequenos e médios proprietários, em torno de 2.500 posseiros com problemas de definição de "suas terras".

Conforme escrito em texto anterior, omomento de maior tensão ocorreu quando milhares de agricultores abandonarem suas terras devido à construção da Hidrelétrica de Itaipu, "um dos projetos implantados nos anos de ditadura com maior impacto na história de 
transformação da natureza e da ecologia do planeta" (cf. Ribeiro, 2002).O consequente represamento das águas para a formação dolago ocasionará o êxodo de vários trabalhadores para outras regiões do país e para o Paraguai e o alagamento de terras cultiváveis.

O país era, então, palco de uma das maiores migrações ocorridas no século XX: a migração para a região norte e noroeste do Brasil, em que milhares de famílias de agricultores partiram em busca de novas terras, principalmente para Rondônia. Nesse contexto, o pequeno agricultor não tinha mais condições de permanecer no Paraná e era forçado a procurar novos horizontes, outra alternativa foi comprar terras no Paraguai, acarretando no fluxo da fronteira entre os dois países se intensificam com a penetração brasileira e com formação da sociedade dos brasiguaios.

Nos pronunciamentos de Kirinus, a má distribuição das riquezas e, portanto, a opressão a que estavam submetidos os pequenos lavradores e os oprimidos, tem relação com a forma com que o país é governado: devido à concentração de riquezas, das terras e dominação dos interesses políticos.No período de que trata Kirinus, isso ocorre de forma mais intensa, pois alguns setores mais progressistas da Igreja aliaram-se aos agricultores na sua luta contra Itaipu, que representava os interesses do Estado. Cabe salientarmos que não eram contrários à instalação da hidrelétrica, mas como seu programa de desapropriação estava sendo instalado ${ }^{4}$. As tensões entre Igreja e Estado fazem parte da história da humanidade.

\footnotetext{
${ }^{4}$ Sobre o duelo que dividia Kirinus entre a religião e a política, encontra-se similar no romance $A$ Montanha Mágica, de Thomas Mann, mediante dois personagens: por um lado, Naphta, que era jesuíta, e contrário à modernidade e ao progresso e pregava uma forma alternativa de distribuição de riquezas e um forte poder da igreja e, do outro lado, Settembrini, um humanista italiano, que acreditava no progresso, na razão e, principalmente na modernidade. Este dualismo de Thomas Mann está presente em Kirinus: ao mesmo tempo em que este questionava a instalação da Hidrelétrica de Itaipu - que significava modernidade, a solução dos problemas energéticos que o país enfrentava naquele momento - não era contrário à sua instalação. Ele era contrário à forma como Itaipu lidava com o problema das desapropriações dos agricultores e reivindicava a necessidade de uma forma mais justa de distribuição de terras.
} 


\section{CADERNOS DO CIM}

ANOI

VOLUME I

№ 1

JANEIRO/JUNHO 2017

PELOTAS/RS

ISSN 2526-5318

Naquele momento, alguns setores religiosos encontravam-se fortemente marcados pela Teologia da Libertação, e Kirinus era um destes adeptos. A Comissão Pastoral da Terra (CPT) surge na região por seu intermédio e com o apoio do bispo católico Dom Frei Agostinho José Sartori, da Diocese de Palmas-Francisco Beltrão (PR).Outra bandeira de luta que defende é o fim do regime militar e a democratização do país.

Kirinus questiona o número de pessoas desaparecidas no Paraná, presos políticos que não retornaram ao seu lar. Com esta preocupação, filia-se ao Movimento Democrático Brasileiro (MDB) ${ }^{5}$, partido de oposição ao governo da Aliança Renovadora Nacional (ARENA). Estes são os principais partidos políticos originários do bipartidarismo imposto pelo Ato Institucional n. 2 (1965) no cenário político brasileiro. A entrada de Kirinus na vida política deu-se inicialmente ao fato de responder a provocações. No seu relato, "em Marechal Cândido Rondon, quando fui participar - a convite, sem maior interesse - do lançamento do Subdiretório do MDB. Como convidado, participei. E fui barrado à entrada do recinto, por um membro da minha igreja, dizendo que eu não deveria participar" (Kirinus, s/d, p. 142).

Kirinus foi criticado por alguns membros de sua igreja e pelos políticos locais da ARENA por participar de reuniões políticas. No jornal, ele contesta esta posição de que, como pastor, não deveria se envolver com política partidária e inicia uma briga que, de acordo com seu depoimento, se estende por dois anos. Segundo ele, o povo paranaense de Marechal Cândido Rondon estava com a ARENA. E foi neste município que a ARENA obteve as mais expressivas vitórias eleitorais no país, motivo da visita do presidente Ernesto Geisel.

\footnotetext{
${ }^{5} \mathrm{O}$ MDB consegue crescer e se fortalecer ao longo da década de 70 , florescendo, sobretudo em dois contextos específicos: onde havia enraizada a tradição das forças políticas que, grosso modo, compunham o grupo político (petebista, pessedista, populista ou das chamadas esquerdas) aliado do poder pelos militares aliados à UDN, e, num segundo momento, em que a prosperidade econômica/ou a urbanização acelerada tornavam a sociedade mais complexa, resultando em mudanças sociais e políticas que trombavam constantemente com a rigidez do modelo de regime engendrado pelo autoritarismo (cf. Melhem, 1998).
} 
Para acabarem com a situação das cidades consideradas áreas de segurança nacional, por meio do autoritarismo dos prefeitos nomeados, e também pela repressão, acreditava-se que a união dos políticos de esquerda libertaria o povo da fronteira brasileira da opressão. Afinal, para nosso narrador, o MDB era o caminho para aluz e para a democracia, que libertaria o povo das injustiças por meio da Associação das Câmaras de Vereadores da Faixa de Fronteira, fundada em 08/07/1978.

Quando já eleito deputado, fazia críticas ao prefeito da cidade, nomeado pelo então governador do Paraná Jayme Canet Junior, e pronunciava-se em favor de eleições diretas na faixa de fronteira ou área de segurança nacional. Como veremos no trecho a seguir,

E lá está nomeado mais um mini-ditador a garantir votos da Arena, através de ameaças a funcionários e professores, como ocorreu recentemente naquele município. Ninguém imagina o despotismo ao qual está submetido aquele povo. E com a nomeação feita recentemente, confirmou-se mais uma vez que Marechal Cândido Rondon irá continuar abandonado aos interesses túrbios de pequenos tiranos que resolveram fazer daquele Município a sede de sobrevivência do III Reich (Kirinus, s/d, p. 24-25).

Marechal Cândido Rondon, segundo Wachowicz (1987) ao comentar sobre a colonização do oeste paranaense, apresenta uma característica marcante, seja "uma das características mais marcantes dessa colonização é a dicotomia italiano-alemã e católicoprotestante. A própria procedência étnica e religiosa dos acionistas de Maripá, condicionou esse processo" (p. 178). E mais, "Willy Barth elegeu o núcleo de Marechal Cândido Rondon para rivalizar com Toledo. Rondon deveria tornar-se o grande centro urbano de origem alemã, com característica religião evangélica luterana" (Wachowicz, 1987, p. 178). 


\section{CADERNOS DO CIM}

Em 1961, a população de Marechal Cândido Rondon elegeu seu primeiro prefeito, Arlindo Lamb. Seu segundo prefeito, eleito em 1965, foi Werner Wanderer, que representava a força jovem do município. Com o desenrolar dos fatos políticos nacionais, o município passa a ser considerado como área de segurança nacional, como toda a faixa de fronteira de Guairá até Foz do Iguaçu. Com isso, os prefeitos passam a ser nomeados e o povo perde o direito de escolher seus representantes.

O município é considerado o mais germânico do Estado. Sua arquitetura, festas e comemorações servem para exaltar este estilo. Inclusive existe, no imaginário da população, uma memória que remonta à tentativa de sobrevivência do III Reich na cidade. Talvez essa memória seja influenciada pelas narrativas que circularam nas décadas de 60-70, de acordo com a pesquisa de Stein (2000), "Os discursos dos anos de 1960 e 1970 apresentavam o município como uma "célula nazista", e abrigaria ex. criminosos de guerra e admiradores do nazismo" (p.33) .

Como em Marechal Cândido Rondon não havia o partido do MDB, Kirinus resolve iniciar um movimento para a formação do partido, ajudando "ferrenhamente" a formar o diretório do $\mathrm{MDB}$, em um trabalho de comunidade de base como era seu ideal de formação política. Acompanhou o desenvolvimento do partido, em um território que era liderado exclusivamente pelos políticos da ARENA e, em 1976, foram nomeados dois vereadores do MDB, fato inédito naquela cidade. Para ele, o MDB representava um partido de resistência à ditadura. Utilizando-nos do seu pensamento, "aproveitando a margem, a fresta de liberdade que nos estava no regime opressor e ditatorial em que vivemos. Fazia uma pregação política" (Kirinus, s/data, p. 143).

\footnotetext{
${ }^{6}$ Interessante a dissertação de mestrado de Marcos Nestor Stein, intitulada $A$ construção do discurso de germanidade em Marechal Candido Rondon (1946-1996). No segundo capítulo, o autor aborda os discursos que na década de 60-70 do século passado, apresentam o município como uma "célula nazista", onde estariam escondidos criminosos de guerra. Fonte: Disponível em: <https://repositorio.ufsc.br/handle/123456789/79286>. Acesso em 26/02/2017.
} 
É interessante observarmos como o tema da liberdade é constante em sua oratória. Não podemos deixar de mencionar que, sob regime ditatorial, as pessoas têm medo de expressar suas opiniões. Por isso, é interessante repararmosnuma imagem recorrente em sua narrativa, seja ela, a imagem da "fresta", do local estreito por onde entra luz e ar, contrário à escuridão. Se relacionarmos ao imaginário ocidental, a escuridão está relacionada às trevas, com a ideia de inferno. Para Kirinus, a luz entrava por uma pequena fresta e era nesta pequena fresta de liberdade que fazia sua pregação política, e, quem sabe, o MDB (naquele contexto era o partido de oposição) conduziria à luz e à liberdade. Se bem compreendemos, a insistência e a repetição da imagem de liberdade estãoligadas ao tema a que dedicou sua militância. Além disso, tem a ver com uma característica particular, pois era duplamente censurado por sua Igreja e pelo Estado. Apesar de o país viver em uma ditadura, o narrador sentia uma maior liberdade ao fazer uso da palavra na tribuna local, que poderia usar para falar mais "das coisas da terra do que do céu".

Esta é uma temática recorrente em vários personagens que vivenciaram este período da ditadura. Na década de 70, o movimento de resistência era muito ativo, aparecia no cinema, música, teatro, literatura, em toda a América Latina. No Brasil, destacaram-se trabalhos de escritores, cantores, jornalistas, educadores, dentre outros. Apenas à título de exemplificação, poderíamos mencionar a obra de um dos maiores artistas deste país, o cantor compositor Francisco Buarque de Holanda. Suas canções fazem parte da memória coletiva do país, em Apesar de você, temos um hino de crítica ao Governo Médici, a ideia de escuridão como cerceamento da liberdade está presente, assim como na narrativa de Kirinus, que vê a liberdade por uma pequena fresta.

Nessa perspectiva, Kirinus continuou um trabalho junto ao diretório de seu partido, chegando a se eleger deputado estadualemblemado como comunista e tachado como "Grupo dos 11". Sua maior atuação foi em defesa dos interesses dos pequenos agricultores. Havia, para ele, dois tipos de violência que expulsavam o homem da terra: uma era a modernização do campo com a mecanização da agricultura; o outro, mais 


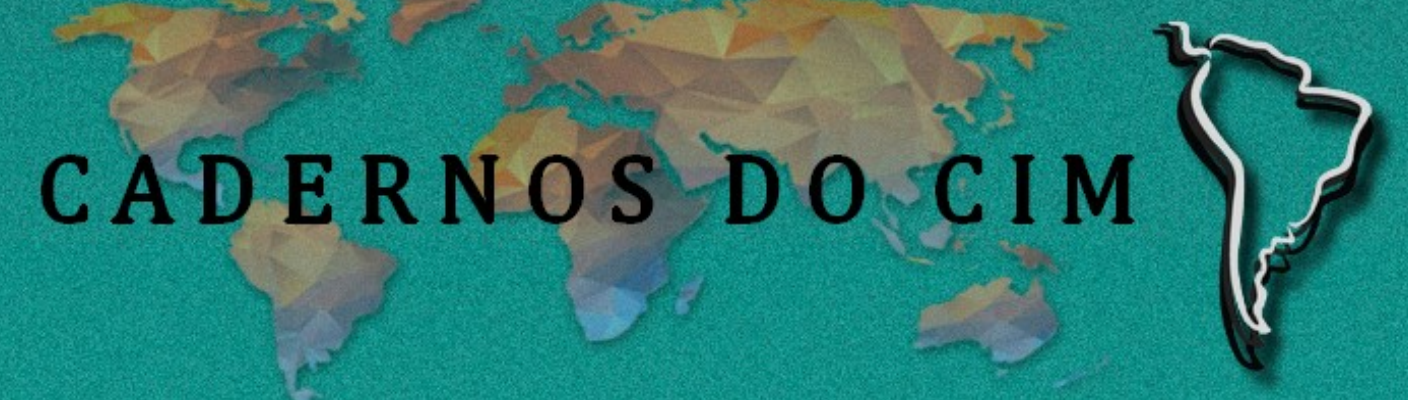

ANO I

VOLUME I

JANEIRO/JUNHO 2017

PELOTAS/RS

ISSN 2526-5318

violento, era o jaguncismo da grilagem da terra. Vejamos seu pronunciamento na Assembleia Legislativa do Paraná em 11/05/79:

O Governo Moysés Lupion inaugurou uma escalada de grilagem de terra, uma verdadeira guerra subversiva contra o nosso povo, não só contra o índio, contra também o lavrador, que tantas mortes já gerou neste Estado e hoje, depois de 30 anos, um acordo desse tipo; depois de trinta anos, grassar a violência em nosso Estado, não só contra o índio, mas também contra o pequeno lavrador, Moisés Lupion continua vivo e solto; continua grilando terras, sob a cobertura de órgãos do Estado e do Governo. Refiro-me à industrial Lupion Ltda., que mantém em cadastro no INCRA as Áreas de "pouso Frio", nos Municípios de Toledo, Marechal Cândido Rondon, enquanto o ITC nos informa que estas terras estão cadastradas no INCRA, de propriedade de Madeireira Rio Paraná Ltda., que colonizou aquela área [...]. Mas a verdade é que ainda em 1979, reclama-se neste país por Justiça e Liberdade; liberdade, por exemplo, de uma escravidão vergonhosa a que estão incluídas varias famílias em nosso Estado que, aqui aportaram em 1950, para trabalhar numa área de terras e que, hoje, em 1979, estão vivendo em apenas 4 alqueires, cercados de arame enfarpado, como se fosse um campo de concentração.Estão encurraladas sob a ameaça de grileiros que se encontram armados, promovendo uma serie de barbaridades. A esses infelizes lavradores, que possuem como armas a enxada e o arado, os grileiros agem com armas em punho, inclusive com armas pesadas, com metralhadora [...]. Aqui no Paraná ainda hoje se mata, se incendeiam casas, se promovem despejos à força com armas pesadas, em áreas de terras em litígios que povoam nosso Estado. Os responsáveis por tais barbarismos de subversão da ordem social continuam ainda livres, e promovendo cada vez mais o 
desentendimento, a desordem, o medo e o terror, a miséria e a morte entre famílias de humildes lavradores, sem que as autoridades constituídas tomem providencias. O que fez até hoje o Governo, para solucionar tais problemas? Ou o Governo está de olhos fechados a tão graves problemas? Porque esta Casa, como a Bancada majoritária ainda continua a dizer que na Oposição estão os vermelhinhos, e que a intenção da oposição é de tumultuar, ao invés de se inteirar dos casos, como os que passamos a relatar (Kirinus, s/d, p. 47).

Em seu pronunciamento, Kirinus evoca um passado de mortes e descaso com o outro, sejam o pobre e o índio. Enfim, para que servem as leis? Para atender aos interesses dos proprietários de terras e dos governantes? E para o povo e os simples trabalhadores, a repressão?

A imagem dos agricultores vivendo em pequeno espaço cercado de arame farpado, comparado com um campo de concentração é uma imagem importante, utilizada inclusive na capa do livro Entre a Cruz e a Política, para representar o massacre e a violência imposta aos lavradores nesta região de fronteira, e para mostrar a brutalidade cotidiana imposta pelos donos de terra e jagunços e o papel do estado frente a problemas tão graves. Observamos a imagema seguir:



Figura 1 - capa do livro Entre a Cruz e a Política

Fonte: Disponível em: acervo da pesquisadora. Acesso em: 03/03/2017. 
Os campos de concentração, para onde foram levados e massacrados milhares de judeus durante a Segunda Guerra Mundial, servem de referência para estabelecer a comparação com o massacre que estava ocorrendo nesta região, onde as pessoas eram cerceadas de toda autonomia e liberdade. A guerra é quase sempre um cenário de destruição. Em sua narrativa, Kirinus conclui em tom de ironia que aqueles que lutam pelo interesse dos oprimidos são estigmatizados de "vermelhinhos" e poderiam representar uma ameaça para a ordem social.

\section{Movimento Justiça e Terra}

Neste ínterim, cabe destacarmos o trabalho de Kirinus junto aos agricultores que foram expropriados de suas terras pela Hidrelétrica de Itaipu. Ao revisarmos a forma como ocorreram as desapropriações de Itaipu, encontramos um dos movimentos políticos mais importantes da região e do país naquele momento, o movimento organizado pelos agricultores que seriam expropriados, com o apoio das Igrejas católica e luterana: o Movimento Justiça e Terra ${ }^{7}$.Este movimento não surge do nada, mas é fruto de um longo trabalho de base, realizado nas capelas e nas igrejas.

A experiência do narrador com dinâmica de grupos, com base também nos ensinamentos de Paulo Freire e sua pedagogia do oprimido, teologia da libertação, foram fundamentais para o rumo que o movimento tomou, e para as lideranças que surgiram entre os agricultores. Assim, o trabalho de basenascia no seio das igrejas, ou seja, nas comunidades, e unia as pessoas em interesses comuns de reivindicação.

\footnotetext{
${ }^{7}$ Os programas de desapropriações foram executados de maneira esparsa nos oito municípios num período compreendido entre 1978 a 1982. Eles abrangeram uma população estimada em aproximadamente 40.000 pessoas, somente do lado brasileiro, conforme os indicativos da Itaipu Binacional.
} 


\section{CADERNOS DO CIM}

As capelas serviam de locais de socialização para os agricultores. Utilizando o Evangelho, "começavam" a descobrir a opressão e as injustiças de que eram vítimas. A partir destes fatos, organizaram-se para a "luta", neste caso, contra Itaipu e seus representantes, exigindo um preço justo pelas suas terras. A Igreja durante o período de construção das grandes obras, construídas nosgovernos militares, esteve preocupada em defender o homem da terra, tendo umavisão ruralista centrada na pequena propriedade. Defendendo esta posição, alguns setores das Igrejas luterana e católica apoiaram a luta gerada no meio deste embate, entre a Itaipu e os agricultores, surgindo na região um dos movimentos mais importantes daquele momento: o Movimento Justiça e Terra, organizado para questionar o valor para a terra. A defesa, também, da perda territorial e de riquezas naturais que o Estado do Paraná sofria frente ao alagamento é outra preocupação da CPT e de alguns políticos (cf. Ribeiro, 2000).

Neste contexto mencionado, as lideranças do Movimento Justiça e Terra, com muita insistência, conseguiram chamar a atenção da opinião pública do Brasil inteiro e os principais jornais do país acompanhavam o desenrolar dos acontecimentos ${ }^{8}$. É importante salientarmos que o pastor foi secretário da CPT até o momento em que este movimento do oeste atingiu a força política necessária para atrair a atenção dos principais jornais do país e do mundo. Naquele momento, os olhares estavam voltados para a grandiosa obra, e as reivindicações dos agricultores ganhavam espaço na mídia, pois contavam com apoio das Igrejas e de muitos políticos do Paraná.

Foi o momento em que surgiu uma "tensão" decorrente da liderança exercida por Kirinus como pastor luterano que, como já mencionamos, não teve o apoio da ala mais conservadora de sua Igreja. De outro lado, a Igreja Católica começou a reivindicar o seu espaço de atuação política, uma vez que o movimento estava então sob o "comando" de

${ }^{8} \mathrm{O}$ Instituto de Terras e Cartografia (ITC) num programa de pesquisa dos preços de terras na região provou que os preços de mercado eram de 491 mil cruzeiros por alqueire de terra nua de 1 . classe. A Itaipu aceitou pagar 470 mil cruzeiros. Antes do movimento, a empresa pretendia pagar 290 mil cruzeiros por alqueire. 


\section{CADERNOS DO CIM}

ANOI VOLUME I № 1 JANEIRO/JUNHO 2017 PELOTAS/RS ISSN 2526-5318

um pastor de outra instituição. Este conflito foi muito interessante entre católicos e protestantes, uma vez que decidiria quem seriao "porta-voz" dos agricultores ${ }^{9}$.

Foi deste movimento, em reunião de agricultores realizado em Medianeira (PR), que surgiu aideia da criação do MASTRO (Movimento do Agricultor Sem Terra no Oeste), movimentoorganizado por trabalhadores sem-terra para reivindicarem o direito de acesso à terra na região.Sob o lema "Unidos Queremos Terra", eles receberam o apoio de sindicatos e de igrejascomprometidascom a luta do homem pela Terra. Nesse viés, o MASTRO deu origem na região ao Movimento Sem Terra (MST) (cf. Ribeiro, 2000).

Atualmente, a luta do MST não diz respeito apenas a questão da terra, de acordo com Pinheiro (2012), "a luta do MST parte de questão da terra, avança nos combate aos problemas da água, dos recursos naturais, da alimentação e contribui para unificar uma perspectiva dos trabalhadores como contraponto a essa situação que atinge o conjunto da sociedade brasileira em seus problemas vitais" (p.59). Congruente ao autor vale destacarmos que, o MST é um dos movimentos sociais de destaque na América Latina.

\section{Considerações finais}

Diante do que foi posto, podemos compreender que a memória pode evitar o esquecimento das lutas populares. E para que não ocorra o esquecimento, é que propomos neste trabalho rememorar a partir da percepção e da narrativa na perspectiva dos vencidos, pois é necessário "escovar a história a contrapelo", como diriaBenjamin (1987, p.225). Utilizando-nos de suas palavras, "nunca houve um monumento de cultura que também não fosse um monumento da barbárie. E, assim como a cultura não é isenta

\footnotetext{
${ }^{9}$ Estas questões do movimento e o rumo que tomou fazem parte da pesquisa sobre a trajetória de Kirinus e sua militância política na região, trazidas no artigo $A$ Reinvenção da Paisagem e os Espaços da Memória (Ribeiro, 2000), publicado no livroPaisagem, território e região: em busca da identidade, de autoria de Álvaro Souza e outros autores.
} 


\section{CADERNOS DOCIM}

de barbárie, não é, tampouco, o processo de transmissão da cultura. Por isso, na medida do possível, o materialista histórico se desvia dela. Considera sua tarefa escovar a história a contrapelo" (Benjamin, 1987. p. 225).

No contexto visto, a memória da luta pela terra foi preservada no Boletim Poeira Material produzido pela Comissão Pastoral da Terra, durante todo o período do embate com a Itaipu, bem como nos pronunciamentos do então deputado Gernote Kirinus. Assim, revisitar esse momento da história e fazer emergir as tensões e os conflitos sobre o uso da terra e sua apropriação, trazendo à tona a problemática terra e homem, são questões que nos moveram no presente trabalho, em tempos em que os direitos, frutosde lutas históricas, estão sendo retirados através de reformas.

O livro Entre a Cruz e a Política traz pronunciamentos no tempo dos acontecimentos e questiona tais eventos, portanto, pode ser considerado contemporâneo a esse tempo, pois, ao questioná-lo percebe os abusos cometidos. Muitas pessoas tinham medo de protestar, serem presas, em outras palavras, vivíamos em um período de silenciamentos, podemos lembrar que o último preso da ditatura militar no Brasil, foi preso na cidade de Foz do Iguaçu.

Nessa conjuntura, a forma como os agricultores organizavam-se é fruto de todo um trabalho em dinâmicas de grupos, de reflexões na esteira da teologia da libertação, fruto dessa formação. Retomemos o fragmento do livro, disposto no seu prefácio que é revelador do seu conteúdo, "a nós não importa ser derrotados ou ser vencedor. O fugir da luta e esconder-nos sob a sombra da tirania".

Assim, o livro é registro da memória de um dos períodos mais complexos da história brasileira. Da história da América do Sul, o Paraguai também vivia em regime ditatorial, e uma parcela paranaense dos expropriados migraram para lá constituindo os brasiguaios. A construção da hidrelétrica de Itaipu é fruto da parceria Brasil e Paraguai, mas essa é outra história. Aqui, o que nos interessa acentuar é que 0 Movimento Justiça e Terra pode nos 


\section{(1)}

ANO I VOLUME I № 1 JANEIRO/JUNHO 2017 PELOTAS/RS ISSN 2526-5318

alertar que sem organização e luta, nossos direitos estarão perdidos, e mais, lembrar que eleserviu de referênciapara um dos movimentos sociais mais bonitos da América Latina, e nesse sentido, revisitar a forma como no passado foi possível reverter as medidas autoritárias, talvez não seja perca de tempo.

\section{Referências}

BENJAMIN, Walter. Magia, técnica, arte e política (obras escolhidas). v.1. São Paulo: Brasiliense, 1987.

DE DECCA, Edgar. Ensaio sobre a memória anarquista: a história como ficção coletiva. In: Revista História Oral. São Paulo, n.2, 1999. p. 111-134.

KIRINUS, Gernote. Entre a Cruz e a Política. Curitiba: Beija-Flor, s/d.

MANN, Thomas. A Montanha Mágica. Rio de Janeiro: Editora Nova Fronteira, 1980.

MELHEM, Célia. Política de botinas amarelas: o MDB-PMDB paulista de 1965 a 1988. São Paulo: Hucitec, 1998.

PINHEIRO, Milton. Operador político, movimentos sociais e lutas antissistêmicas. In: $A$ reflexão marxista sobre os impasses do mundo atual. Organização de Milton Pinheiro. São Paulo: Outras Expressões,2012. p.25-71.

RIBEIRO, Maria de Fátima. A reinvenção da paisagem e os espaços da memória. In: Paisagem, território e região. Organização de Àlvaro de Souza et al. Cascavel: Edunioeste, 2000.p.259-273.

. Memórias do concreto: vozes na construção de Itaipu. Cascavel: Edunioeste, 2002. 


\section{CADERNOS DOCIM}

\section{(5)}

ANO I VOLUME I № 1 JANEIRO/JUNHO 2017 PELOTAS/RS ISSN 2526-5318

SAMUEL, Raphael. Teatros da Memória. Projeto História. Revista do Programa de Estudos Pós-Graduados em História e do Departamento de História da PUC/SP. São Paulo, n.14, 1997. p.41-81.

SOSNOWSKI, Saul. Contraos consumidores do esquecimento. In: O trânsito da memória. Organização de Jorge Schwartz e Saul Sosnowski. São Paulo: Editora da Universidade de São Paulo, 1994.

STEIN, Marcos. A construção do discurso da germanidade em Marechal Cândido Rondon (1946-1996). 2000. 147 f. Dissertação de mestrado. Universidade Federal de Santa Catarina, Centro de Filosofia e Ciências Humanas. Florianópolis, mar. 2000.

WACHOWICZ, Ruy. Obrageros, mensus e colonos: história do oeste paranaense. 2. ed. Curitiba: Vicentina, 1987.

WHITE, Hayden. Trópicos do Discurso: ensaios sobre a crítica da cultura. São Paulo: EDUSP, 1999. 